\title{
Measuring the efficiency of wastewater services through Data Envelopment Analysis
}

\author{
A. Guerrini*, G. Romano**, C. Leardini*, M. Martini* \\ * Department of Business Administration, University of Verona, Via dell'Artigliere, 19, \\ 37129 Verona, Italy \\ (E-mail: andrea.guerrini@univr.it; martina.martini@univr.it; chiara.leardini@univr.it) \\ ** Department of Economics and Management, University of Pisa, Via Ridolfi, 10, 56124 \\ Pisa, Italy \\ (E-mail: giulia.romano@ec.unipi.it)
}

CIWA Publishing 2015. The definitive peer-reviewed and edited version of this article is published in WATER SCIENCE AND TECHNOLOGY, v. 71, n. 12, pp. 1845-1851 (2015)

[DOI: 10.2166/wst.2015.169] and is available at www.iwapublishing.com.

\begin{abstract}
Efficient water management is a priority for the European Union (EU), as the operational efficiency of water utilities in many EU countries is low compared to best practice benchmarks. Several countries are restructuring their water utilities sectors to improve cost savings. Large-scale operations and vertical integration strategies are being promoted to achieve scale and scope economies; however, there are no results in current literature to support the effectiveness of such measures. Additionally, limited data are available on the effect of customer density on costs. This study offers some insight into these issues by using a two-stage Data Envelopment Analysis (DEA) approach to analyse the Danish water industry, with the aim of investigating the presence of scale, scope and density economies in the wastewater segment. Research findings show that the Danish wastewater segment is characterised by scope and density economies: utilities providers that serve more than 100 inhabitants per km of sewerage mains, and contextually offer water and wastewater services, achieve the best standard of efficiency. Scale is shown to have minimal influence on global efficiency, even where purely technical efficiency decreases when company sizes increase.
\end{abstract}

Keywords: Data envelopment analysis; economies of density; economies of scale; economies of scope; wastewater

\section{Introduction}

The European Union (EU) considers efficient water management a priority. Many scholars have attempted to highlight the existence of economies of scale and scope in this industry to develop a comprehensive framework for facilitating managerial and political decision making, but results remain inconclusive (Berg and Marques 2011; Carvalho et al. 2012; Guerrini et al. 2013; Saal et al. 2013).

As highlighted by Abbott and Cohen (2010), there is agreement that economies of scale exist in relation to wastewater activities, although there is no clarity on exactly where they start. 
However, this consensus may have developed because wastewater industry research has received little attention, with most studies focusing on entities undertaking water supply as well as wastewater activities (Ashton 2000; Romano and Guerrini 2011). While there is considerable evidence that scope economies exist for water production and distribution (Saal et al. 2013), results from studies on the joint provision of water and wastewater services differ, such as those focused mainly on the United Kingdom and Portugal (see Guerrini et al. 2013; Saal et al. 2013). As the literature on economies of density in the water industry is scarce (Berg and Marques 2011; Guerrini et al. 2013), further empirical studies are required.

This study aims to contribute to the literature on economies of scale in the wastewater segment by investigating the potential presence of economies of scale, scope and customer density within a previously unanalysed context. Denmark provides an ideal setting in which to compare the cost drivers for wastewater utilities, as it is characterised by the presence of companies of different sizes and with different strategies. The findings of this study contribute to the ongoing debate regarding the best organisational choices for water utilities providers by offering new policy directions for the implementation of carefully chosen strategies. The influence of cross-cultural noise is eliminated by focusing on a single country, allowing the study to specify the optimal size, degree of investment diversification and population density to produce the maximum level of efficiency in the results (Carvalho et al. 2012; Guerrini et al. 2013).

This article begins by providing an overview of the Danish water and wastewater segments, followed by a description of the research method, paying particular attention to the process of data collection and analysis. The key findings of the study are then outlined, showing how the selected operational and environmental variables affect the efficiency of water utilities. Finally, the main implications for government policy are discussed.

\section{Danish Water Industry}

The Danish water industry, organised into four river basin districts, is highly decentralised, with 98 municipalities responsible for providing water and wastewater services to 5.58 million inhabitants in an area of $42895 \mathrm{~km}^{2}$ (Statistics Denmark 2013). The municipalities monitor water operators and are responsible for the use, planning and protection of water, including water quality, water supply and wastewater infrastructure.

Similar to other European countries, such as Austria and Sweden, Denmark allows private sector participation by not-for-profit companies. Data from 2006 show that in the drinking water segment, about $60 \%$ of the Danish population is served by public operators owned by municipalities, while the remaining $40 \%$ is served by private operators in the form of consumer cooperatives and not-for-profit companies. Public operators supply the more populated areas, while private operators prevail in villages (EUREAU 2009). The drinking water segment includes production, based mainly on groundwater, and distribution through a network of $41000 \mathrm{~km}$. More than 2000 utilities providers are involved in supplying drinking water; however, of these, 80 municipal water utilities providers supply approximately twothirds of all water. Conversely, wastewater operators are almost all public companies; in only limited instances have these private companies been contracted by municipalities to carry out operations. 
The Danish water industry underwent important reform in 2009, aimed at enhancing its quality and efficiency. In particular, the Water Sector Reform Act (Vandsektorloven, Law no. 469/2009) introduced four main changes (Sørensen 2010):

1. establishment of a regulatory authority

2. obligatory corporatisation

3. state-driven performance benchmarking

4. incentive-based price regulation.

The regulatory authority, the Utility Secretariat, assessed the appropriateness of price regulation, carried out benchmarking and assumed control of water and sewerage utilities, to offer high-quality services at low prices. The regulator also determines price caps and exemptions from maximum prices, and at least annually publishes prices and the results of benchmarking. The Utility Secretariat also reports on its activities to the Minister of the Environment.

According to the theories of new public management and new public governance (Hood 1991; Clark 2000; Osborne 2006), corporatisation requires the separation of regulatory functions from operational functions, the adoption of professional business management strategies, with greater transparency and accountability, and for public utilities providers to apply the principles and managerial tools typical of private companies (Shleifer and Vishny 1994).

Mandatory benchmarking allows water utilities processes to be compared with outcome performance and identifies opportunities for improvement through learning from best practice. With comparable experiences to the Portuguese and Dutch, Denmark has introduced competition in the water sector to enhance efficiency and quality (Marques 2006; De Witte and Saal 2010). To integrate mandatory benchmarking, the Utility Secretariat has the support of the Danish Water and Wastewater Association (DANVA), which has conducted voluntary benchmarking since 1999 (DANVA 2010).

Other countries have used benchmarking similarly. In England and Wales, the Water Services Regulation Authority (OFWAT) applied Data Envelopment Analysis (DEA) models and regression to set prices (Dassler et al. 2006). Up until 1994, the Italian Regulatory Authority set water tariff variables based on the cost functions of selected water utilities (Antonioli and Filippini 2001). Until 2011, Denmark set prices by applying the break-even principle; that is, water prices covered the costs of water protection, catchment, treatment and distribution, while wastewater prices covered the costs of drainage, treatment and discharge. Prices varied depending on structural factors (e.g., population density, age of plants and geographical features) and political policies (e.g., investment choices and funding arrangements). From 2011, price caps were applied and, from 2012, they were based on benchmarking results. The caps aimed to provide efficiency incentives: companies that reduced their costs should make profits, and although such profits had to be reinvested in the sector, companies' consolidation level could be enhanced (Sørensen 2010).

Denmark's water utilities industry accounts for $1.4 \%$ of the European water industry, which was valued at US\$260.1 billion in 2011. The Danish water industry is differentiated from other European countries by certain features and sets interesting parameters for the investigation undertaken during this study. Denmark's water industry is characterised by:

- low population density: 129.7 inhabitants per square kilometre (inh/ $\mathrm{km}^{2}$ ) in 2011 , greater than the density of Spain $\left(92 \mathrm{inh} / \mathrm{km}^{2}\right)$ and France $\left(103 \mathrm{inh} / \mathrm{km}^{2}\right)$, similar to that of Portugal $\left(114.5 \mathrm{inh} / \mathrm{km}^{2}\right)$, but lower than that of Italy $\left(201.5 \mathrm{inh} / \mathrm{km}^{2}\right)$, Germany 
(229 inh/ $\left.\mathrm{km}^{2}\right)$, England and Wales $\left(371 \mathrm{inh} / \mathrm{km}^{2}\right)$ and the Netherlands $\left(494.5 \mathrm{inh} / \mathrm{km}^{2}\right)$ (Eurostat 2011)

- a high level of decentralisation: more than 2000 utilities providers, with an average population of 2059 inhabitants served per provider (inh/utility), which is much fewer than in Germany (13 $667 \mathrm{inh} /$ utility), Italy (648 $352 \mathrm{inh} / \mathrm{utility})$ and England and Wales (2 148000 inh/utility) (Carvalho et al. 2012)

- one of the highest tariffs in Europe: the unit price of water and wastewater services to Danish households in 2007-08, including taxes, was US\$6.70 per cubic metre $\left(\mathrm{m}^{3}\right)$ (OECD 2010)

- one of the lowest water loss rates: the difference between water volumes pumped out and water volumes registered by consumers was only $1.7 \mathrm{~m}^{3}$ per $\mathrm{km}$ of pipes per day in 2009 (DANVA 2010).

\section{Method and Results}

The DANVA benchmarking report (DANVA 2011) lists 101 Danish water utilities providers that delivered water services in Denmark in 2010. In that year, they supplied approximately $54 \%$ of the Danish population with drinking water and treated wastewater for approximately $65 \%$ of the population. Of these, 39 companies supplied only drinking water, while 44 provided wastewater transport and treatment services. The remaining 18 firms provided both services to their customers. These water companies administered 1966 bores, 239 waterworks, $26615 \mathrm{~km}$ of distribution networks and $49139 \mathrm{~km}$ of sewer networks. In total, they provided 205 million $\mathrm{m}^{3}$ of clean water to approximately 3 million inhabitants and treated 581 million $\mathrm{m}^{3}$ of wastewater, covering 3.6 million inhabitants. For this study, data on the 62 wastewater utilities providers were collected, including the populations served, length of sewers, financial statistics and annual sales volumes. The financial data specifically referred to information on wastewater management: transport costs, treatment costs and customer handling costs, reported in Danish krone (DKK).

The dataset analysed in this study consists of 372 items on these 62 utilities providers. Table 1 contains the data that reveal notable differences in the sizes of the populations served.

Table 1: Descriptive Statistics of the Sample Observed

\begin{tabular}{|c|c|c|c|c|}
\hline Wastewater utilities & Max & Min & Mean & SD \\
\hline Operation costs (DKK) & $\$ 147296850$ & $\$ 5331962$ & $\$ 39925518$ & $\$ 29723605$ \\
\hline Volume of water inflow $\left(\mathrm{m}^{3}\right)$ & 11812097 & 626287 & 3113549 & 2026060 \\
\hline Sewer length & 2496 & 55 & 819 & 494 \\
\hline Population served & 533875 & 8486 & 61470 & 84074 \\
\hline $\begin{array}{l}\text { Population density } \\
\text { (population/km of sewerage } \\
\text { mains) }\end{array}$ & 3849 & 16 & 146 & 498 \\
\hline
\end{tabular}

The dataset was divided into different groups to gather more knowledge of the sample. Firstly, water utilities providers were categorised as mono- or multi-utilities. The former consisted of providers that delivered wastewater services only, while the latter featured providers offering both services (water and wastewater). Secondly, considering the population served to kilometres of sewerage ratio, four groups of approximately equal size were identified based on customer density: very high density (VHD), high density (HD), low 
density (LD) and very low density (VLD). Using these criteria, three groups of equal size (large, medium and small companies) were identified based on population served.

The method applied is consistent with Guerrini et al. (2013) and comprises two main stages. Stage 1 determines DEA scores for 101 Danish utilities providers, using data on costs and volumes of water sold to obtain constant return to scale technical efficiency (CRSTE), variable return to scale technical efficiency (VRSTE) and scale efficiency (SE). While CRSTE measures the overall efficiency, VRSTE measures the actual capability of a decisionmaking unit (DMU) to purchase, mix and consume inputs, and SE indicates the effectiveness of the decision to operate with a certain production scale. DEA is used as a non-parametric technique to determine a frontier and calculate an efficiency ratio for each unit observed. Through a linear programming approach, DEA identifies an efficient virtual producer for each unit; the efficiency ratio is the distance separating the virtual unit from the real unit (Charnes et al. 1978; Banker et al. 1984).

If efficiency is measured by the capability to reduce consumption of input at a given level of output, the input and output quantities to use in the DEA model must be carefully chosen. In accordance with data available in the 2011 DANVA benchmarking report, three inputs were used: transport, treatment and customer handling costs, while the output measured was volume of water settled in the sewer catchment area, equal to volume of water sold.

Stage 2 includes a regression analysis of the efficiency scores obtained through DEA (dependent variable) and operational and environmental variables (independent variables): company size, the degree of investment diversification and population density. A Tobit regression function was chosen for describing the relationship between a non-negative dependent variable (restricted between zero and one) and the independent variables. This twostage approach is not perfect (Simar and Wilson 2007). DEA scores are expected to correlate, as the calculation of efficiency of one utilities provider requires observation of all other providers. Thus, with the problem of multiple collinear factors, robust regression analysis cannot be conducted. Despite this limitation, the chosen two-stage method offers the most appropriate way to answer the questions posed by this study, considering its widespread use (Renzetti and Dupont 2009; Byrnes et al. 2010). Additionally, the two-stage method is more effective than alternative approaches, such as the one-stage parametric method (Banker and Natarajan 2008), OLS, the Papke-Wooldridge Method and the unit-inflated beta model (Hoff 2007).

\section{Results and Discussion}

The efficiency scores for Danish utilities providers presented in Figure 1 show some weaknesses. Wastewater providers in the dataset demonstrate poor performance (CRSTE 0.36; VRSTE 0.48; and SE 0.78), which implies that they could reduce consumption of inputs for at least $64 \%$ without any output decrease. Only $13 \%$ of firms operate near the VRS frontier, with a VRSTE between 0.90 and 1.00, while the majority have a score between 0.20 and 0.40 . These low scores on 'pure technical efficiency' are only partially compensated for by SE: the difference between the VRS and CRS frontiers (as measured by SE) is not significantly high, with $35 \%$ of the observed utilities providers operating at a potentially optimal scale (SE 0.90-1.00). 


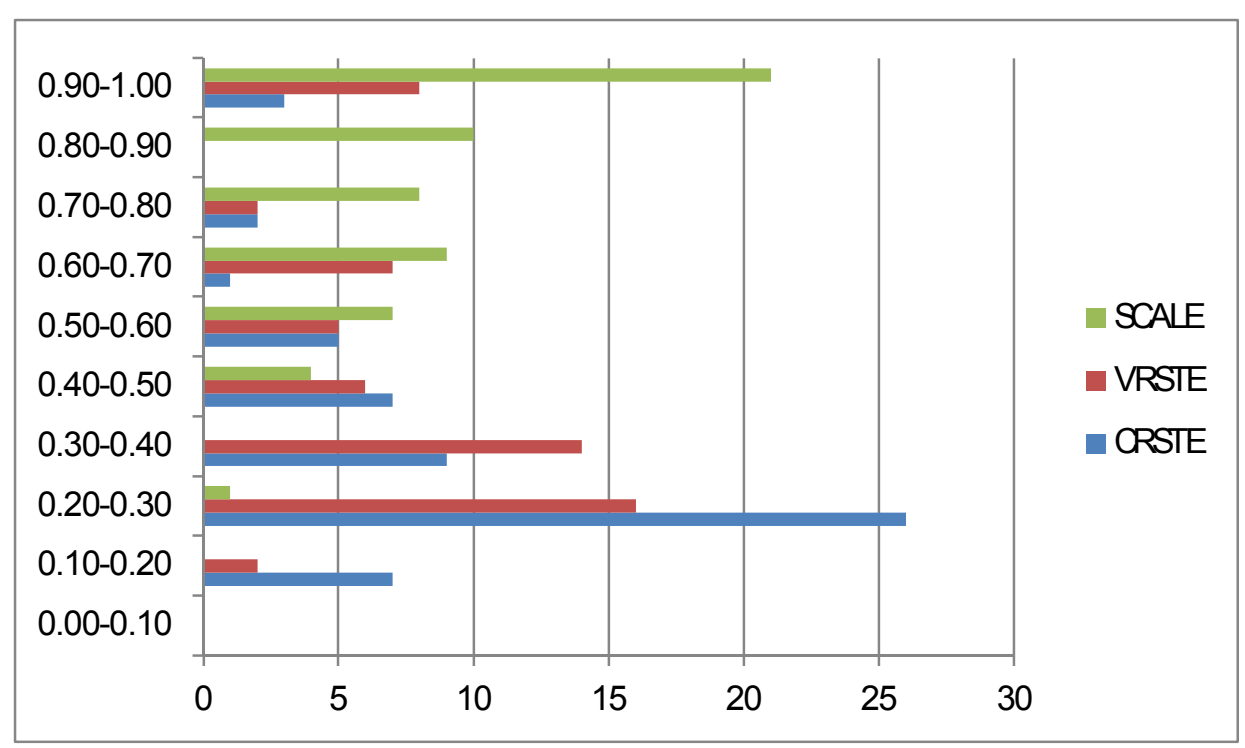

Figure 1: Efficiency Distribution of Danish Wastewater Utilities

Table 2 provides DEA scores for each group, highlighting significant differences across the four groups involved in wastewater services. The study found that utilities providers serving more than 100 inhabitants per km of sewerage mains (the VHD group) achieved the best standard of global efficiency and were easily able to purchase, combine and consume inputs to treat a cubic metre of wastewater. Nevertheless, approximately $47 \%$ of the observed companies operated under the critical threshold of 40-50 inhabitants per km of sewer and demonstrated weak performance. Apart from servicing residential areas that are more compact where possible, there are few solutions for utilities providers for dealing with low population density. Considering that the sewerage coverage rate in Denmark is $100 \%$ (WHO/UNICEF 2006), the solution of activating new connections to improve customer density is not feasible. These results are confirmed by the regression analysis: global and pure technical efficiency linearly increase with rising population density.

Examining Table 2, which indicates that the water and wastewater group achieves the best performance, the policy of most Danish local municipalities to separate water and wastewater services, by using a different utilities provider for each within the same geographical area, seems to penalise performance. However, this result is only partially confirmed by the statistical analysis, since CRSTE is positively affected by a wider scope of operations, but with a low level of significance $(p>0.05)$. Consequently, further research should be conducted before increasing the scope of wastewater utilities providers to achieve improved efficiency.

Finally, utility company size resulted in two contrasting efficiency scores (SE and VRSTE), with the effects of each neutralising the other when global efficiency is a factor. Large companies achieved optimal structure; however, pure technical efficiency decreased as scale of operations increased. These results imply that strategies aiming to expand the markets served by wastewater utilities providers (e.g., covering new geographic areas or company consolidation) fail to yield cost savings. 
Table 2: DEA Scores and Differences across Groups in the Wastewater Segment.

CRSTE VRSTE SE

\begin{tabular}{llll}
\hline Size & & & \\
Large & 0.392 & 0.436 & 0.920 \\
Medium & 0.365 & 0.486 & 0.749 \\
Small & 0.279 & 0.470 & 0.672 \\
Diversification & & & \\
Water and wastewater & 0.423 & 0.515 & 0.826 \\
Wastewater & 0.309 & 0.445 & 0.751 \\
Density & & & \\
Very high density & 0.609 & 0.473 & 0.832 \\
High density & 0.285 & 0.359 & 0.839 \\
Low density & 0.286 & 0.479 & 0.630 \\
Very low density & 0.246 & 0.337 & 0.804 \\
\hline
\end{tabular}

Table 3: Regression Analysis in the Wastewater Segment

Tobit

\begin{tabular}{lllllll} 
regression & CRSTE & $\mathbf{p}>\mathbf{t}$ & VRSTE & $\mathbf{p}>\mathbf{t}$ & $\mathbf{S E}$ & $\mathbf{p}>\mathbf{t}$ \\
\hline $\begin{array}{l}\text { Size } \\
\text { Water and }\end{array}$ & -0.047 & 0.145 & -0.271 & $0.001 * * *$ & 0.237 & $0.002 * * *$ \\
wastewater & 0.091 & $0.079 *$ & -0.007 & 0.874 & 0.061 & 0.226 \\
Density & 1.17 & $0.003 * * *$ & 3.29 & $0.000^{* * *}$ & -0.165 & 0.267 \\
\hline \multicolumn{5}{c}{$(* * *, * *$ and * indicate $1 \%, 5 \%$ and $10 \%$ significance levels, respectively) }
\end{tabular}

\section{Conclusions}

This study addressed the performance of wastewater utilities providers, with the aim of contributing to the ongoing scientific and political debate on the most efficient way to organise and manage such companies. The research contributes to existing literature on performance measures for providers operating in the water industry by applying a combined DEA and regression analysis method to the wastewater segment. Research findings highlighted that Danish wastewater utilities providers achieve low-level efficiency on average, with significant differences between wastewater service groups. Providers that operate in areas of very high population density (with more than 100 inhabitants per $\mathrm{km}$ of sewerage mains) achieved the highest standard of efficiency and companies that offer water and wastewater services achieve the best overall performance. Additionally, differently sized providers delivered contrasting results on efficiency scores.

Practical implications arising from this study are manifold. Firstly, national water authorities and utilities providers should consider the effect of population density on performance. Water authorities should include this environmental variable in any benchmarking model adopted, to avoid negatively influencing providers' performance and thus concentrate on the service management capabilities of providers. (Denmark's Utilities Secretariat takes this approach, adjusting the main output of providers, measured by volume of water sold, according to population density.) This would allow providers to pursue acquisition of other wastewater utilities operating in areas of high population density and reduce their overall costs. Further, water authorities and utilities providers could investigate the installation of small-scale treatment plants in rural and isolated areas to reduce, or eliminate, the cost of wastewater transportation, which is the variable most affected by population density. 
Further studies are required to support existing data on the effect of efficiencies generated by vertical integration policy. Panel data and cross-country datasets could be developed to further analyse economies of scale, scope and density in the wastewater segment of the water industry.

\section{References}

Abbott M. and Cohen B. 2010 Industry structure issues in the water and wastewater sectors in Australia. Economic Papers 29, 48-63.

Antonioli B. and Filippini M. 2001 The use of a variable cost function in the regulation of the Italian water industry. Utilities Policy 10, 181-187.

Ashton J. 2000. Total factor productivity growth and technical change in the water and sewerage industry. Service Industries Journal 20, 121-130.

Banker R. D. and Natarajan, R. 2008 Evaluating contextual variables affecting productivity using data envelopment analysis. Operations Research 56, 48-58.

Banker R. D., Charnes, A. and Cooper, W. W. 1984 Some models for estimating technical and scale inefficiencies and data envelopment analysis. Management Science 32, 30 44.

Berg, S. V. and Marques, R. C. 2011 Quantitative studies of water and sanitation utilities: a literature survey. Water Policy 13, 591-606.

Carvalho, P. and Marques, R. C. 2013 Computing economies of vertical integration, economies of scope and economies of scale using partial frontier nonparametric methods. European Journal of Operational Research doi: http://dx.doi.org/10.1016/j.ejor.2013.09.022

Carvalho, P., Marques, R. C. and Berg, S. 2012 A meta-regression analysis of benchmarking studies on water utilities market structure. Utilities Policy 21, 40-49.

Charnes, A., Cooper, W. W. and Rhodes, E. 1978 Measuring the efficiency of decision making units. European Journal of Operational Research 2, 429-444.

Clark, D. 2000 Public service reform: a comparative west European perspective. West European Politics 23, 25-44.

DANVA 2010 Water in figures: DANVA's benchmarking and water statistics 2010. http://www1.danva.dk/Admin/Public/DWSDownload.aspx?File=/Files/Filer/Udgivels er/Benchmarking/Vand $+\mathrm{i}+$ tal/Water in Figures 2010.pdf

DANVA 2011 Water in figures: DANVA benchmarking 2011: process benchmarking and statistics. http://www.e-pages.dk/danva/100

Dassler, T., Parker, D. and Saal, D. S. 2006 Methods and trends of performance benchmarking in UK utility regulation. Utilities Policy 14, 166-174.

De Witte, K. and Saal, D. S. 2010 Is a little sunshine all we need? On the impact of sunshine regulation on profits, productivity and prices in the Dutch drinking water sector. Journal of Regulatory Economics 37, 219-242.

Guerrini, A., Romano, G. and Campedelli, B. 2013 Economies of scale, scope and density in the Italian water sector: a two-stage data envelopment analysis approach. Water Resources Management 27, 4559-4578.

Hoff, A. 2007 Second stage DEA: comparison of approaches for modelling the DEA score. European Journal of Operational Research 181, 425-435.

Hood, C. 1991 A public management for all seasons. Public Administration 69, 3-19.

Marques, R. C. 2006 A yardstick competition model for Portuguese water and sewerage services regulation. Utilities Policy 14, 175-184.

Osborne, S. 2006 The new public governance? Public Management Review 8, 377-387. 
Renzetti, S. and Dupont, D. 2009 Measuring the technical efficiency of municipal water suppliers: the role of environmental factors. Land Economics 85, 627-636.

Romano, G. and Guerrini, A. 2011 Measuring and comparing the efficiency of water utility companies: a data envelopment analysis approach. Utilities Policy 19, 202-209.

Saal, D. S., Arocena, P., Maziotis, A. and Triebs, T. 2013 Scale and scope economies and the efficient vertical and horizontal configuration of the water industry: a survey of the literature. Review of Network Economics 12, 93-129.

Shleifer, A. and Vishny, R. W. 1994 Politicians and firms. The Quarterly Journal of Economics 109, 995-1025.

Simar, L. and Wilson, P. W. 2007 Estimation and inference in two-stage semi-parametric models of production processes. Journal of Econometrics 136, 31-64.

Sørensen, E. M. 2010 The Danish Water Sector Reform-Economic Efficiency and CentralLocal Relations. Danish Institute of Governmental Research, Copenhagen, Denmark.

Denmark in Figures 2013, Statistics Denmark, Copenhagen, Denmark.

WHO/UNICEF, 2006. Joint Monitoring Programme for Water Supply and Sanitation. II World Health Organization. III.UNICEF. 